\title{
A hygiene report regarding slaughter process of pig and cattle carcasses for 2017 in Serbia
}

\author{
Lazar Milojevic', Brankica Lakicevic ${ }^{1}$,Vesna Jankovic ${ }^{1}$, Radmila Mitrovic ${ }^{1}$, Aleksandra Nikolic ${ }^{l}$, \\ Milijana Babic ${ }^{2}$,Branko Velebit ${ }^{1}$
}

A b s t r a c t: For the successful validation and verification of the HACCP system, a food business operator is obliged, among other duties, to have continuous microbiological data of carcasses which are followed by a certain dynamic that the subject himself prescribed. To obtain these data, it is necessary to perform systematic monitoring of indicator microorganisms. The most important meat hygiene indicators are Total Viable Counts (TVC) and Enterobacteriaceae (EC). TVC are defined as indicators of overall slaughter hygiene (equipment, environment, tools, workers), while EC are indicators of faecal contamination on carcasses. The aim of this study was to determine the microbial contamination of cattle and pig carcasses, level of hygiene of the slaughter process as well as whether variations hygiene levels were related to seasonality in Serbia during 2017. The year was divided into four quarters of three months each, while the microbiological results were classified into three levels of hygiene status (unsatisfactory, satisfactory or acceptable). The highest percentage of the results surveyed during the entire study was at a satisfactory hygiene level. Furthermore, we found there were differences in results between the quarters, which could be associated with seasonality. The best microbiological results, and so the best hygiene of carcasses, was recorded in the period April, May, June, while the worst microbiological results were observed in the period of July, August and September.

Keywords: slaughterhouse, process hygiene, Total Viable Count, Enterobacteriaceae, seasonality.

\section{Introduction}

Meat consumption is increasing worldwide due to rapid population growth and urbanization. This has resulted in increased concerns and challenges when it comes to meat safety and hygiene. Therefore, the meat safety regulations should be implemented from farm, slaughterhouse, processing, storage, distribution, retail outlets up until the products reach the consumers (Sofos and Geornaras, 2010). During the food production process, each step of production is controlled and has a set of specific rules. The process of hazard analysis and critical control point (HACCP) is a systematic, science-based approach process control, designed to prevent, reduce or eliminate identified hazards in food products (Kukay et al. 1996). Therefore, a food business operator (FBO) is obligated to achieve compliance with these regulations. FBOs must apply compulsory self-checking programs following the HACCP approach.

The slaughterhouse is an indispensable part of the meat processing chain, being the place where animals are humanely killed to produce meat and meat products, and the entire process is under the supervision of an official veterinarian. Codex Alimentarius guidelines deal with hygiene of animals presented for slaughter: "the degree of contamination of the external surfaces of the animal is likely to compromise hygienic slaughter and dressing, and suitable interventions such as washing, or shearing are not available" (Codex Alimentarius, 2005). Regulation EU 853/2004 lists requirements that FBOs operating slaughterhouses must comply with, and one of them is that animals must be clean. Strict maintenance of good abattoir hygiene practices is of central importance to ensure both public health protection and meat quality. Implementation of good manufacturing practices (GMP) as well as HACCP for slaughterhouses and meat processing facilities plays a major role in enhancing the safety of meat products (Bohaychuk et al., 2011). Generally, it is accepted that the HACCP approach is the most effective way of reducing or eliminating contamination during food processing. For successful implementation of a HACCP system, it is necessary to have data on microbiological contamination, since the carcasses

1Institute of Meat Hygiene and Technology, Kacanskog 13, 11000 Belgrade, Republic of Serbia;

${ }^{2}$ University of Belgrade, Faculty of Veterinary Medicine, Bulevar Oslobodjenja 18, 11000 Belgrade, Republic of Serbia.

Corresponding author: Lazar Milojevic, lazar.milojevic@inmes.rs 
can be contaminated despite the absence of visible dirt (Tergney and Bolton, 2006). Scientific research has shown that with regard to long-term hygienic conditions in abattoirs, regular microbiological examination of the carcasses provides reliable conclusions (Zweifel and Stephan, 2003). This microbiological data can also be used for compliance with abattoir-specific performance criteria (Zweifel et al., 2005). In order to obtain these data, it is necessary to perform systemic monitoring of indicator microorganisms (Brown et al., 2000).

Regulation (EC) No. 2073/2005 and Serbian Regulation (Official Gazette of the Republic of Serbia, No. 72/10, 2011) require the obligatory control of hygiene indicators in slaughter processes. The most important meat hygiene indicators are Total Viable Counts (TVC) and Enterobacteriaceae (EC). TVC are defined as indicators of overall slaughter hygiene (equipment, environment, tools, workers), while EC are indicators of faecal contamination on carcasses (Martelli et al. 2017). Following the indicator microorganisms, allows indirect monitoring of the presence of pathogenic microorganisms such as Salmonella spp., Listeria monocytogenes, Campylobacter jejuni/coli, Escherichia coli and Yersinia enterocolitica (Nørrung et al., 2009). These food-borne pathogens are still considered as important sources of human infections (Nørrung et al., 2009).

Analysis of data which were collected from slaughterhouses in Serbia in 2017 was conducted to understand the microbiological contamination of cattle and pigs carcasses, as well as establish the level of hygiene of the slaughter process for each animal. Further analysis of the obtained data should establish whether there are any variations in the hygiene results and if they exist, any relationship with seasonality.

\section{Materials and methods}

\section{Abattoirs and carcass sampling}

The study encompassed abattoirs with different production capacities in Serbia, and which were regularly subjected to veterinary inspection. A total of 554 wetdry swabs were collected during one year for cattle carcasses and 769 swabs were collected for pig carcasses. Following national regulations on the general and specific food hygiene requirements, we took samples in the production and processing phases. The number of samples by month was in line with the selfcontrol plans developed by HACCP teams in every abattoir. Samples were obtained by the wet-dry swab technique from four different sites
(4 × $100 \mathrm{~cm}^{2}$; cattle: neck, brisket, flank, and rump; pig: back, cheek, ham, and belly) of one half of each chosen carcass, as stipulated by SRPS ISO 17604 (ISO, 2016). Sampling was conducted by an authorized and trained laboratory technician and swabs were taken from five cattle and/or five pig carcasses randomly selected at the end of slaughter line, after the final wash but before chilling. Sample testing was performed by an ISO 17025 (ISO, 2005) accredited laboratory in accordance with respective ISO methods for TVC and EC enumeration.

\section{TVC and Enterobacteriaceae enumeration}

Each sample, consisting of four swabs, was added to $100 \mathrm{~mL}$ BPW (Oxoid, UK) and homogenized for $1 \mathrm{~min}$ in a stomacher (Laboratory Blender, Stomacher 400). TVC was obtained by inclusion of $1 \mathrm{~mL}$ of the suspension (M) and a series of 10 -fold dilutions $\left(10^{-1}, 10^{-2}, 10^{-3}\right)$ in duplicate into Plate Count Agar plates ([PCA] Oxoid, UK). EC counts were obtained by spread plating $1 \mathrm{~mL}$ of the suspension (M) and a series of 10 -fold dilutions $\left(10^{-1}\right.$, $\left.10^{-2}, 10^{-3}\right)$ in duplicate onto Violet Red Bile Glucose Agar plates ([VRBGA] Oxoid, UK). Five characteristic colonies per plate were confirmed following SRPS ISO 21528-2:2009 (oxidase test and glucose fermentation test). The media was incubated as described above, according to SRPS EN ISO 4833-1:2014 and SRPS ISO 21528-2:2009. TVC and EC were calculated according to SRPS EN ISO 7218:2008/A1:2014. Bacterial recovery was expressed as $\log _{10}$ colony-forming units (cfu) $/ \mathrm{cm}^{2}$ and calculated as described in SRPS ISO 18593:2010, using the following formula:

cfu $\mathrm{cm}^{-2}=\mathrm{N} \times \mathrm{F} / \mathrm{A} \times \mathrm{d}$

$\mathrm{N}=$ the number of cfu in $1 \mathrm{~mL}$ of dilution liquid (or neutralizing liquid);

$\mathrm{F}=$ the amount, in millilitres, of dilution fluid (or neutralizing liquid) in the tube or homogenizer bag;

$\mathrm{A}=$ is the area swabbed, in square centimetres;

$\mathrm{d}=$ is the dilution corresponding

\section{Analysis of results}

The year was divided into four quarters of three months. The first quarter (Q1) was January, February and March, the second quarter (Q2) comprised April, May and June. The third (Q3) comprised July, August and September, while October, November and December made up the fourth quarter (Q4).

All carcasses were classified into the following hygiene categories: unsatisfactory, satisfactory 
and acceptable, according to Anonymous (2017). For cattle carcasses, unsatisfactory results were those counts above $4.3 \log \mathrm{cfu} \mathrm{cm}^{-2}$ for TVC and above $1.8 \mathrm{log} \mathrm{cfu} \mathrm{cm}^{-2}$ for EC. Acceptable results were those counts below $4.3 \log \mathrm{cfu} \mathrm{cm}^{-2}$ for TVC and below $1.8 \log \mathrm{cfu} \mathrm{cm}^{-2}$ for EC. Satisfactory results were those equal to or below $2.8 \log \mathrm{cfu} \mathrm{cm}^{-2}$ for TVC and equal to or below $0.8 \log \mathrm{cfu} \mathrm{cm}^{-2}$ for EC. Pig carcasses were deemed unsatisfactory if they had more than $4.3 \log \mathrm{cfu} \mathrm{cm}^{-2}$ TVC and more than $2.3 \log \mathrm{cfu}$ $\mathrm{cm}^{-2}$ for EC; acceptable pig carcasses had less than $4.3 \log \mathrm{cfu} \mathrm{cm}^{-2}$ for TVC and less than $2.3 \log \mathrm{cfu}$ $\mathrm{cm}^{-2}$ for EC. Microbial levels on satisfactory pig carcasses were equal to or below $3.3 \log \mathrm{cfu} \mathrm{cm}^{-2}$ for TVC and equal to or below $1.3 \log \mathrm{cfu} \mathrm{cm}^{-2}$ for EC.

The obtained microbial results/data were analysed using Microsoft Office Excel 2016.

\section{Results and Discussion}

In Serbia in 2017, cattle carcass contamination levels ranged from $0.0 \log \mathrm{cfu} \mathrm{cm}^{-2}$ to $3.7 \log \mathrm{cfu} \mathrm{cm} \mathrm{cm}^{-2}$ for TVC and from $0.0 \log \mathrm{cfu} \mathrm{cm}^{-2}$ to $2.4 \log \mathrm{cfu} \mathrm{cm}^{-2}$ for $\mathrm{EC}$, while pig carcass contamination levels ranged from $0.0 \mathrm{log} \mathrm{cfu} \mathrm{cm}^{-2}$ to $3.88 \mathrm{log} \mathrm{cfu} \mathrm{cm}^{-2}$ for TVC and $0.0 \log \mathrm{cfu} \mathrm{cm}^{-2}$ to 2.7 $\log \mathrm{cfu} \mathrm{cm} \mathrm{cm}^{-2}$ for EC.

\section{Cattle carcasses}

\section{TVC values for cattle carcasses}

In Q1, TVC levels on cattle carcasses were within the satisfactory range (equal to or less than $2.8 \log \mathrm{cfu} \mathrm{cm}^{-2}$ ) in $85.5 \%$ of tested cattle carcasses, while in $14.5 \%$ of tested carcasses, TVC levels were within the acceptable range, between 2.8-4.3 $\log \mathrm{cfu} \mathrm{cm}^{-2}$. In Q2, 92.86\% of tested carcasses were classified in the satisfactory hygiene group, and the remaining $7.14 \%$ were in the acceptable group. Altogether in Q3, 85.62\% of carcasses belonged to the satisfactory group, while the rest $(14.38 \%)$ were within the acceptable group. In Q4, we established that $82.71 \%$ of carcasses belonged in the satisfactory group, while the remaining $17.29 \%$ were classified in the acceptable group (Figure 1).

\section{EC values for cattle carcasses}

EC levels in Q1 were lower than $0.8 \log$ cfu $\mathrm{cm}^{-2}$ in $95.42 \%$ of tested carcasses, which therefore, belonged to the satisfactory group, while $3.05 \%$ had a level between $0.8 \log \mathrm{cfu} \mathrm{cm}^{-2}$ and $1.8 \log \mathrm{cfu} \mathrm{cm}^{-2}$, which put them in the acceptable group. Some cattle carcasses $(1.53 \%)$ had an EC level higher than $1.8 \log \mathrm{cfu} \mathrm{cm}^{-2}$, and therefore, they belonged to the unsatisfactory group. In Q2, 97.14\% of pig carcasses belonged to the satisfactory group and the remainder $(2.86 \%)$ belonged to the acceptable group. In the third quarter, EC levels on cattle carcasses were within the satisfactory range in $86.93 \%$ of tested cattle carcasses, while in $7.84 \%$ of tested carcasses, EC levels were within the acceptable range and the remaining $5.23 \%$ of carcasses were within the unsatisfactory group. In Q4, 88.72\% of tested carcasses belonged to satisfactory group, $7.52 \%$ of carcasses were within the acceptable range and 3.76\% were classified as unacceptable (Figure 2).

\section{Pig carcasses}

\section{TVC values for pig carcasses}

The results of tested pig carcasses in Q1 showed that for TVC, 97\% fell into the satisfactory group (equal to or less than $3.3 \log \mathrm{cfu} \mathrm{cm}^{-2}$ ), while $3 \%$ belonged to the acceptable group (4.3-3.3 $\left.\log \mathrm{cfu} \mathrm{cm}^{-2}\right)$.

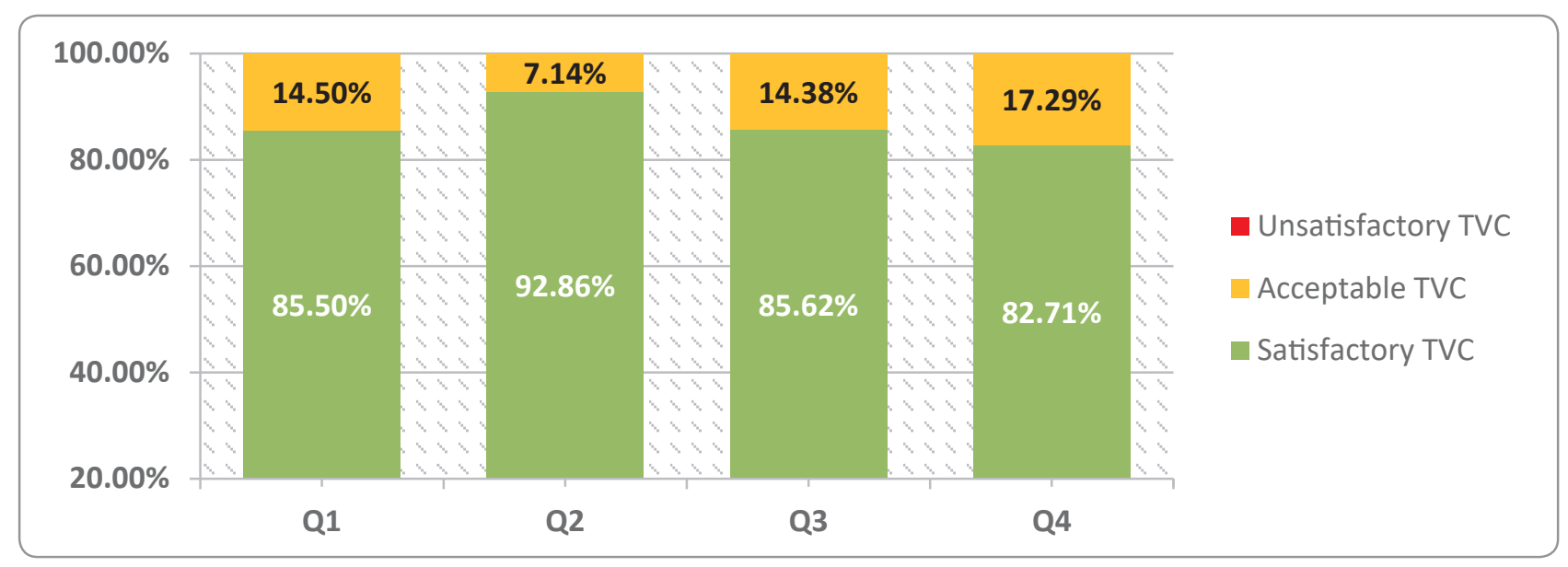

Figure 1. Trend analysis of Total Viable Count for cattle carcasses in 2017 


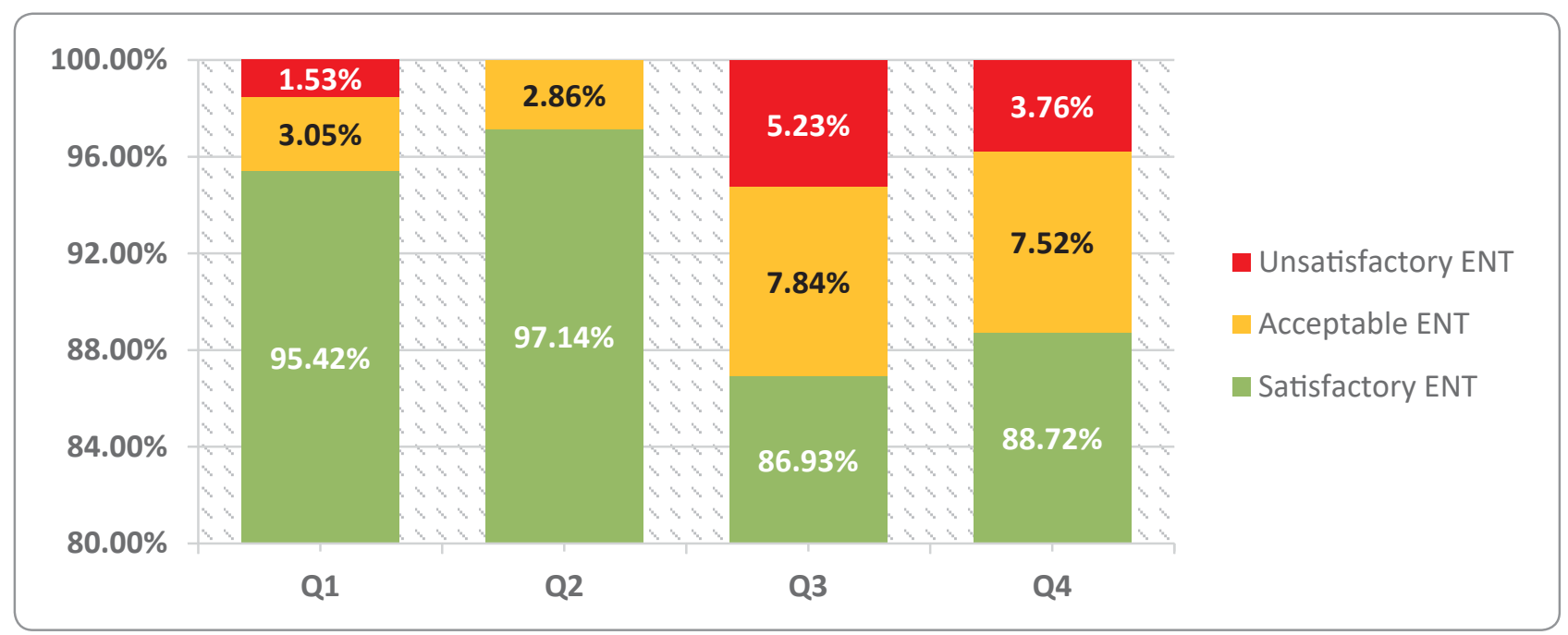

Figure 2. Trend analysis of Enterobacteriaceae for cattle carcasses in 2017

In Q2, 99\% of tested carcasses were within the satisfactory group, and $1 \%$ were within the acceptable group. In Q3, 98\% of tested carcasses belonged to the satisfactory group and $2 \%$ of pig carcasses belonged to the acceptable group. In Q4, 96\% of pig carcasses belonged to the satisfactory group, while $4 \%$ of tested carcasses were within the acceptable group (Figure 3).

\section{EC values for pig carcasses}

EC values for pig carcasses in Q1 were such that $99 \%$ of tested pig carcasses belonged to the satisfactory group (equal to or less than $1.3 \log \mathrm{cfu} \mathrm{cm}^{-2}$ ) and $1 \%$ of carcasses belonged to the acceptable group $\left(1.3-2.3 \log \mathrm{cfu} \mathrm{cm} \mathrm{cm}^{-2}\right)$. Similar results were observed in remaining quarters, where $99 \%$ of tested carcasses in Q2, 98\% in Q3 and 96\% in Q4 were within the satisfactory group, while 1\% of pig carcasses in Q2, $2 \%$ in Q3 and 4\% in Q4 belonged in the acceptable group. In Q3, 1\% of tested carcasses were classified in the unsatisfactory group (Figure 4).

TVC and EC are indicators for hygiene process in slaughterhouses (Delhalle et al., 2008). Following these two parameters indicates the overall hygiene (TVC) in the slaughterhouses, as well as faecal contamination (EC) of the carcasses. In 2017 (divided into four separate periods), we observed that over $82 \%$ of the studied cattle carcasses had satisfactory TVC levels $\left(\leq 2.8 \log \mathrm{cfu} \mathrm{cm}^{-2}\right)$. However, the results were different for each quarter. Among the four annual quarters, Q2 had the highest percentage of carcasses with satisfactory hygiene status according to TVC levels. After that time, the percentage of carcasses with satisfactory hygiene status decreased

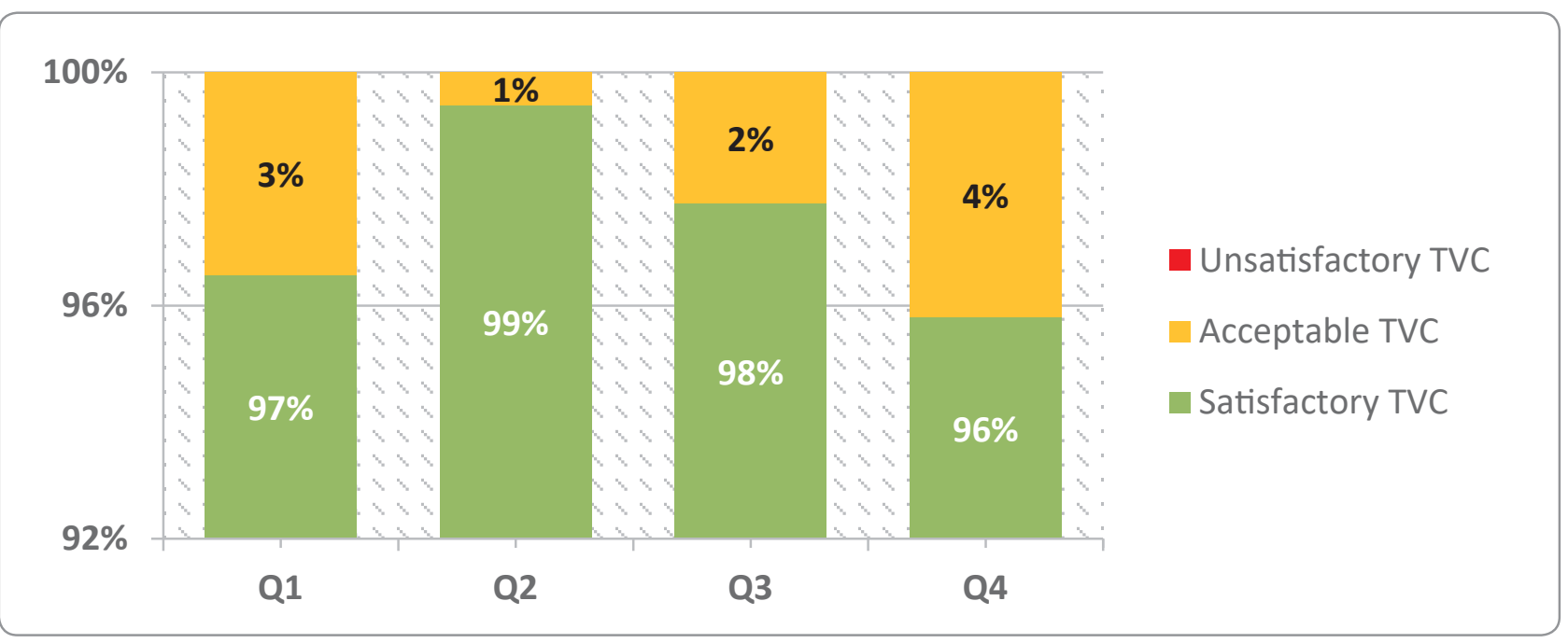

Figure 3. Trend analysis of Total Viable Count for pig carcasses in 2017 


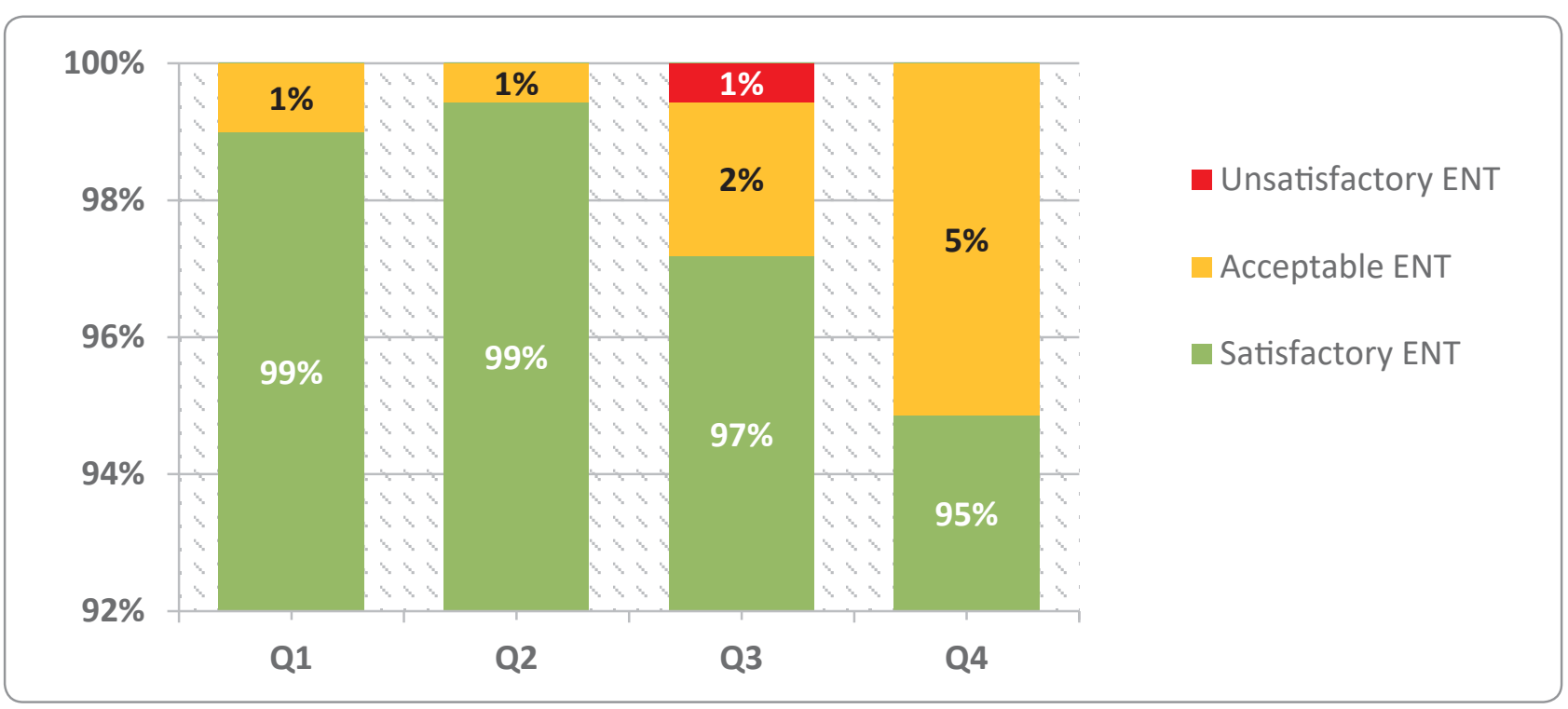

Figure 4. Trend analysis of Enterobacteriaceae for pig carcasses in 2017

during Q3 and Q4. Q4 had the highest percentage of carcasses with acceptable hygiene status according to TVC levels. Similar results were obtained for EC levels, where the highest percentage of carcasses with a satisfactory hygiene status was observed in Q2. Q1, Q3 and Q4 were periods when carcasses had unsatisfactory EC levels ( $\left.>4.3 \log \mathrm{cfu} \mathrm{cm}^{-2}\right)$, and this was especially true for Q3, when over 5\% of carcasses had unsatisfactory EC levels. This difference between quarters can probably be related to the colder and warmer parts of the year. Rony et al. (2007) came to a similar conclusion in their research, in which they confirmed the differences in the microbial levels on carcasses between these two periods of the year. Barco et al. (2014) highlighted that the season appears to have a direct impact on EC counts on beef carcasses, associating low counts with the dry season and cold months. Every step from the farm, through transport, storage, general hygienic conditions in the slaughterhouse and activities before and during slaughter can have an impact, which can be seen by microbiological analysis. If we observe the farm, during the warmer months, animals use a higher amount of water; they also try to cool down in different ways. All of this results in a higher percentage of dirty animals, and therefore, a special focus on animals with dirt of faecal origin is required during the hotter, summer months. The transport of animals to slaughterhouses in the summer months should be given special attention, since any failure made during transport will have consequences on the microbiological results of the carcasses. The hide of dirty animals is the most important source of contamination for carcasses, in particular during skinning operations. Bacteria including important foodborne pathogens can be transferred from hides onto carcasses via direct or indirect contact (Brichta-Harhay et al., 2008). By the fact that the animals are dirtier, the possibility of contamination of the carcasses is greater. Nastasijevic et al. (2008) stated that in cattle carcass processing, one of the main concerns is related to observed soil and faecal contamination of carcasses and cross contamination during storage. The percentage of cattle carcasses which belonged to the unsatisfactory group in our study is probably because these carcasses had a greater potential for contamination with EC (Zweifel et al., 2004). It should also be noted that slaughterhouses of different sizes were included in the current study.

Treatment of pig carcasses is different from cattle carcasses, because during pig processing, the carcasses pass through various characteristic and specific technological procedures. Due to this, microbiological contamination of pig carcasses is specific and one should expect different microbiological results and hygiene status compared to cattle carcasses. Raseta et al. (2015) obtained medium levels of $2.87 \mathrm{log} \mathrm{cfu} \mathrm{cm}^{-2}$ for TVC and $1.05 \mathrm{log}$ $\mathrm{cfu} \mathrm{cm}^{-2}$ for EC levels on pig carcasses in a single slaughterhouse located in Banat, Serbia, for a period of one year. Out of all pig carcasses examined in our study, over $95 \%$ of them belonged to the satisfactory group. Observing TVC, the yearly period with the highest percentage of carcasses belonging to the satisfactory hygiene group was Q2, while the worst results occurred during Q4. Similarly poor results were obtained for EC in Q3, during which some carcasses were classified in the unsatisfactory group. 
These results differ from the results of Mrdovic et al. (2017) who carried out research in one district in Serbia and found that TVC levels of pig carcasses were within the satisfactory range in $74.33 \%$ of tested carcasses and EC levels of carcasses were within satisfactory range in $100 \%$, for a period of six years (2011-2016). These variations of results could reflect the improvement of hygienic conditions in slaughterhouses, which naturally, is an objective to strive for.

\section{Conclusion}

The hygienic conditions of slaughter are a focal point in the food chain. Despite the challenge of analysing results obtained from slaughterhouses of different sizes, the results obtained in this study indicate that the highest percentage of carcasses have satisfactory/acceptable levels of TVC and EC contamination. These results showed that most of the examined slaughterhouses keep managing and maintaining high quality standards. However, the percentage of carcasses with higher levels of TVC and/or EC contamination, and so classified as unsatisfactory, shows there are still opportunities for improvement. Attention must be paid to every link in the food chain from the farm, through the transport, residence of the animals in lairage and on the slaughter processing line in order to achieve the best performance. Hygiene in a slaughterhouse must be at a high level, as must the education of workers who should have regular training in accordance with new scientific knowledge. A high degree of hygiene and quality should be maintained throughout the year. Special attention should be paid during the summer months, during which a higher percentage of carcasses classified as unsatisfactory from the point of view of microbial contamination was observed in this survey.

Disclosure statement: No potential conflict of interest was reported by authors.

\section{References}

Anonymous (2017). Meat Industry Guide - Chapter 13 Microbiological Criteria, Food Standards Agency, London, UK.

Barco, L., Bellico, S., Roccato, A. \& Ricci, A. (2014). Escherichia coli and Enterobacteriaceae counts on pig and ruminant carcasses along the slaughter line, factors influencing the counts and relationship between visual fecal contamination of carcasses and counts: A review. EFSA supporting publication 2014: EN-634, 111.

Bohaychuk, V. M., Gensler, G. E. \& Barrios, P. R. (2011). Microbiological baseline study of beef and pork carcasses from provincially inspected abattoirs in Alberta, Canada. The Canadian Veterinary Journal, 52 (10), 1095-1100.

Brown, M. H., Gill, C. O., Hollingsworth, J., Nickelson, I. R., Seward, S., Sheridan, J. J., Stevenson, T., Sumner, J. L., Theno, D. M., Usborne, W. R. \& Zink, D. (2000). The role of microbiological testing in systems for assuring the safety of beef. International Journal of Food Microbiology, 62 (7), 16.

Brichta-Harhay, D. M., Guerini, M. N., Arthur, T. M., Bosilevac, J. M., Kalchayanand, N., Shackelford, S. D., Wheeler, T. L. \& Koohmaraie, M. (2008). Salmonella and Escherichia coli O157:H7 contamination on hides and carcasses of cull cattle presented for slaughter in the United States: an evaluation of prevalence and bacterial loads by immunomagnetic separation and direct plating methods. Applied and Environmental Microbiology, 74, 6289-6297.

Codex Alimentarius (2005). Code of hygienic practice for meat ${ }^{1}$ CAC/RCP 58-2005: 1-51

Delhalle, L., De Sadeleer, L., Bollaerts, K., Farnir, F., Saegerman, C., Korsak N. et al. (2008). Risk factors for Salmonella and hygiene indicators in the 10 largest Belgian pig slaughterhouses. Journal of Food Protection, 71 (7), $1320-1329$

EC (2005). Commission Regulation (EC) No 2073/2005 of 15 November 2005 on microbiological criteria for foodstuffs (vol. L 338). Brussels, Belgium: European Commission. Official Journal of the European Union.

EFSA (2004) Clean Beef Cattle for slaughter. A guide for producers. Published by the Food Standard Agency November 2004, Crown Copyright 2004, Printed in England 5k FSA/0951/1104.

International Organization for Standardization (ISO) (2009). Microbiology of food and animal feeding stuffs Horizontal methods for the detection and enumeration of Enterobacteriaceae - Part 2: Colony count method. ISO 21528-2:2009, Geneva, Switzerland.

International Organization for Standardization (ISO) (2014). Microbiology of food and animal feeding stuffs - Horizontal method for the enumeration of microorganisms - Colony count technique at 30 degrees C. ISO 4833-1:2014, Geneva, Switzerland.

International Organization for Standardization (ISO) (2007). Microbiology of food and animal feeding stuffs - General requirements and guidance for microbiological examinations. ISO 7218:2007. Geneva, Switzerland.

International Organization for Standardization (ISO) (2005). General requirements for the competence of testing and calibration laboratories. ISO 17025:2005. Geneva, Switzerland.

International Organization for Standardization (ISO) (2016). Microbiology of the food chain - Carcass sampling for microbiological analysis SRPS EN ISO 17604:2016. 
Kukay, C. C., Holcomb, L. H., Sofos, J. N., Morgan, J. B., Tatum, J. D., Clayton, P. P. \& Smith, G. C. (1996). Applications of HACCP by small-scale and medium-scale meat processors. Dairy, Food and Environmental Sanitation 16 (2), 74-80.

Martelli, F., M. Lambert, P. Butt, T. Cheney, F. A. Tatone, R. Callaby \& R. P. Smith. (2017). Evaluation of an enhanced cleaning and disinfection protocol in Salmonella contaminated pig holdings in the United Kingdom. PLoS ONE, 12(6), e0178897. http://doi.org/10.1371/journal. pone.0178897.

Ministry of Agriculture, Forestry and Water Management Serbia. (2010). Ordinance on general and specific food hygiene requirements at any stage of production, processing and trade. Republic of Serbia. Official Gazette of the Republic of Serbia. No. 72/10.

Mrdovic, B., Raseta, M., BrankovicLazic, I., Milijasevic, M., Baltic, B., \& Nastasijevic, I. (2017). Pigs and cattle slaughter process hygiene in a largescale and a smallscale abattoir: A report from one county in Serbia. Meat Technology, 58 (2), 65-72.

Nastasijevic, I., Mitrovic, R., \& Buncic, S. (2008). Occurrence of Escherichia coli $\mathrm{O} 157$ on hides of slaughtered cattle. Letters in Applied Microbiology, 46 (1), 126-131.

Nørrung, B., J. K. Andersen \& S. Buncic. (2009). Main concerns of pathogenic microorganisms in meat. In: Todra F. (Ed) Safety of Meat and Processed Meat (Food Microbiology and Food Safety). Springer, New York, USA, pp. 3-30 (ISBN 978-0-387 89025-8).
Raseta, M., Teodorovic, V., Jovanovic, J., Lakicevic, B., LazicBrankovic, I. \& Vidanovic, D. (2015). The hygiene of the process of slaughtering and processing of pigs for one year on one slaughterhouse in the North Banat District in Serbia. Meat Technology, 56 (1), 26-3.

Ruby, J., Zhu, J., Ingham, S. (2007). Using indicator bacteria and Salmonella test results from three large-scale beef abattoirs over an 18-month period to evaluate intervention system efficacy and plan carcass testing for Salmonella. Journal of Food Protection, 70 (12), 2732-2740.

Sofos, J. N. \& Geornaras. I. (2010). Overview of current meat hygiene and safety risks and summary of recent studies on bio-films and control of Escherichia coli O157:H7 in non-intact and Listeria monocytogenes in ready to eat meat products. Meat Science, 86, 2-14.

Tergney, A. \& Bolton, D. J. (2006). Validation studies on an online monitoring system for reducing faecal and microbial contamination on beef carcasses. Food Control, 17, 378-382.

Zweifel, C., Baltzer, D. \& Stephan, R. (2005). Microbiological contamination of cattle and pig carcasses at five abattoirs determined by swab sampling in accordance with EU decision 2001/471/EC. Meat Science, 69, 559-566.

Zweifel C. \& Stephan R. (2003). Microbiological monitoring of sheep carcass contamination in three Swiss abattoirs. Journal of Food Protection, 66, 946-952. 